\title{
Addressing challenges in using breath chemical analysis in smartphone-based health diagnostics
}

\author{
Julia Vamvakari \\ T4i Engineering Ltd \\ The Advanced Technology \\ Innovation Centre (ATIC) \\ Oakwood Drive \\ Loughborough \\ Leicestershire \\ LE11 3QF \\ jvamvakari@t4i.co.uk
}

\author{
George C. Pallis \\ T4i Engineering Ltd \\ The Advanced Technology \\ Innovation Centre (ATIC) \\ Oakwood Drive \\ Loughborough \\ Leicestershire \\ LE11 3QF \\ gpallis@t4i.co.uk
}

\author{
Pawel Mochalski \\ Breath ResearchInstitute, \\ University of Innsbruck \\ Rathausplatz 4 \\ A-6850 Dornbirn \\ 00435572204674
}

Pawel.Mochalski@uibk.ac.at

\author{
Felipe Fernandez \\ Department ATSI ETSIINF, \\ Polytechical University of Madrid \\ (UPM) \\ Campus de Montegancedo \\ 28660 Madrid \\ +341913367372 \\ felipe.fernandez@es.bosch.com \\ Milt Statheropoulos \\ School of Chemical Engineering, \\ National Technical University of \\ Athens (NTUA), Field Analytical \\ Chemistry and Technology Unit \\ 9 Iroon Polytechniou Str., \\ 15773 Athens, Greece \\ stathero@chemeng.ntua.gr
}

\author{
Ivo Ramos Maia Martins \\ Atos S.A. \\ C. Albarracin 25 \\ 28037 Madrid, Spain \\ ivo.ramos@atos.net
}

\author{
Juan Mario Rodríguez \\ Atos S.A. \\ C. Albarracin 25 \\ 28037 Madrid, Spain \\ juan.rodriguezp@atos.net
}

\begin{abstract}
Volatile organic compounds (VOCs) emitted by the human body (via e.g. breath, skin, urine, or saliva) offer unique and noninvasive insight into physiological and medical status of an individual. The analysis of this volatile chemical signature emerges as a promising and powerful approach for detecting and tracking infections, cancer development, metabolic disorders, progression of therapeutic intervention, as well as, individual's exposure to environmental pollutants and/or toxins. The rationale behind this approach is that the observed chemical pattern is unique and disease specific, thereby, can be distinguished from
\end{abstract}

patterns related to other physiological states (both normal and abnormal). Amongst different physiological fluids breath holds in this context a distinguished status as it is readily and noninvasively obtainable and relatively non-complex. Moreover, its volatile and semi volatile constituents have already been demonstrated to provide valuable information on various disease processes occurring in the human body. A number of sophisticated analytical techniques e.g. Gas ChromatographyMass Spectrometry (GC-MS), GC-MS/MS, High Performance Liquid Chromatography-Mass Spectrometry (HPLC-MS), Selective Reagent Ionization - Time of Flight - Mass Spectrometry (SRI-TOF-MS), Ion Mobility Spectrometer (IMS) have been involved to recognize and define the disease-specific chemical fingerprints. Integrating chemical sensors or more sophisticated chemical instrumentation with mobile phones will lead to a number of potential personalized health applications. However a number of challenges exist that need to be addressed; disease specific gases and/or VOCs in breath must be credible, repeatable and unambiguous. This is perhaps one of the biggest challenge due to a number of reasons such as potential 
dependence of the type and concentrations of VOCs on various parameters (e.g. individuality, gender, geographic area). In this context, the characteristic VOCs in breath related to renal failure are presented and discussed in this work. Another challenge is the degree of the chemical instrument/sensor miniaturization and how this can affect performance of analytical methods. There is also the challenge of developing faster, user friendly, cost/effective applications for mobile phones.

\section{Keywords}

Exhaled air; breath; breath chemical analysis; volatile organic compounds (VOCs); chemical sensors; renal failure; mobile phones; remote medical diagnostics

\section{INTRODUCTION}

Volatile organic compounds (VOCs) emitted by the human body (via e.g. breath, skin, urine or saliva) offer unique and noninvasive insight into physiological and medical status of an individual. The analysis of this volatile chemical signature emerges as a promising and powerful approach for detecting and tracking infections, cancer development, metabolic disorders, progression of therapeutic intervention, as well as, individual's exposure to environmental pollutants and/or toxins. The rationale behind this approach is that the observed chemical pattern is unique and disease specific, and, thereby can be distinguished from patterns related to other physiological states (both normal and abnormal). Amongst different physiological fluids breath holds in this context a distinguished status as it is readily and noninvasively obtainable and relatively non-complex. Moreover, its volatile and semi volatile constituents have already been demonstrated to provide valuable information on various disease processes occurring in the human body. For instance, chemical fingerprints identified in human breath proved to be useful for recognition of lung cancer, gastric cancer, or breast cancer. Thus this novel diagnostic approach has a huge potential to become an alternative to the conventional diagnostic methods, or at least their valuable supplement.

VOCs are compounds with relatively high vapor pressure that are present in human expired air. Specific VOCs in breath are product of metabolic processes and are closely linked with medical information. The concept of using chemical breath analysis in combination with mobile phones for remote medical diagnostics is quite challenging $[1,2]$. The detection of VOCs in breath can be related to diagnosis and monitoring of diseases and metabolic disorders such as cancer, diabetes, asthma and liver or renal failure. A number of analytical chemical methods (e.g. IMS, MS) exist that are capable of providing detection and identification of VOCs (and gases) contained in expired air.

The last years there is a strong trend in reducing the size and weight of traditional bench top lab instruments such as GC, GCMS, MS, IMS, as well as, a tendency for miniaturization of those instruments. A review of miniaturized mass spectrometry systems has been recently presented in [3]. In addition great advancements in communications allow for building robust, credible, low cost solutions in remote medical diagnostics; this is especially true for mobile phones. The combination of well established VOCs markers of diseases and metabolic disorders with miniaturization of credible, robust, ultralow limit of detection chemical detectors can provide potentiality for full integration with mobile phones preparing the next generation of remote medical diagnostics based on chemical diagnostics[2].

\section{CHALLENGES IN USING BREATH ANALYSIS WITH MOBILE PHONES}

A number of sophisticated analytical techniques (e.g. GC-MS, GC-MS/MS, HPLC-MS, SRI-TOF-MS, IMS) have been involved to recognize and define the disease-specific chemical fingerprints [1]. Unfortunately, the analytical instruments provided by these techniques are inherently bulky, expensive, demand laborious and time-consuming sample-preparation methods, and require welltrained and experienced operators. This places significant limitations on their routine application as medical diagnostics. Here, simple-in-use ("yes/no" response), rapid, hand-held, lowpower and simultaneously sensitive diagnostic tools are desirable. Sensor-based or miniaturized detectors integrated with a mobile phone could meet these requirements.

Integrating chemical sensors or more complicated chemical instrumentation with mobile phones will lead to a number of potential personalized health applications. However a number of challenges exist that need to be addressed; disease specific gases and/or VOCs in breath must be credible, repeatable and unambiguous. This is perhaps one of the biggest challenge due to a number of reasons such as potential dependence of the type and concentrations of VOCs on various parameters (e.g. individuality, gender, geographic area). Another challenge is the degree of chemical instrument/sensor miniaturization and how this can affect performance of analytical methods. There is also the challenge of developing faster, user friendly, cost/effective applications for mobile phones.

\section{PLATFORMS FOR DEVELOPING APPLICATIONS}

New methods and technologies have been developed with the scope of using mobile phones in biomedical diagnosis, food processing and environmental monitoring. Android OS has been built with the philosophy of allowing the development of a new generation of devices, sensors and applications. Connecting external sensors other than chemical sensors has been widely done both for experimentation and commercial interests. As an example, Arduino chips and IOIO boards have become popular in this task. Communication is usually accomplished via Bluetooth or USB-OTG cable between the external device and the mobile phone that also provides personal communication and internet access. This makes Android platform a candidate tool for analysis in remote locations with high throughput and low cost. Breath analysis is a promising field to apply mobile computing platforms capabilities [2]. Despite the benefits, there are potential communication limitations that need to be improved such as: internet communication reliability, the possibility of privacy leak and the need to establish the use of better standards and validation practices to ensure the proper use and integration of these sophisticated tools into medical practice and grant the increasing quality and safety of the apps.

Relevant research effort is currently ongoing. There are also announcements for potential commercial products, such as Breathometer (https://www.breathometer.com), that was finally launched after a social campaign for funds ended in March 2015. It is a device attached to the smartphone that provides information about breath quality and hydration. These apps are commonly focused in Blood Alcohol Content (BAC), e.g. BACtrack (http://www.bactrack.com) and the above mentioned Breathometer. More focused in healthcare, Vantage mHealthcare (http://vantagemhealthcare.com) is developing a sensor that will 
screen for the VOCs signature in a person's breath and aims to identify the presence of lung cancer.

A systems methodology for mobile health has been previously referred [4]. Presently, a big number of health wearable Bluetooth sensors are developed for the global market. Future developments will be mainly based on advancements in biomarkers, smart nanosensor technologies, low power wireless communication, and power supply technologies. Today especially promising wearables development ecosystems are the cloud-IoT approaches from Apple [5] and Samsung [6]. The software-hardware platformecosystems from Texas Instruments and Intel are also very interesting for the practical development of the involved mobile breath analysis devices for medical applications [7-10].

\section{ADDRESSING THE CREDIBILITY CHALLENGE OF THE DISEASE SPECIFIC VOCs: THE RENAL FAILURE CASE}

One type of renal failure is the chronic kidney disease. The prevalence of chronic kidney disease (CKD) increased continuously over the last decades. Currently, more than $7 \%$ of the population over 30 have a glomerular filtration rate below $60 \mathrm{ml} / \mathrm{min} / 1.73 \mathrm{~m} 2$ [11]. CKD usually is a progressive disorder demanding treatment by transplantation or dialysis. Although dialysis is lifesaving, overall patient mortality by far exceeds that of an age matched population without CKD. This stems at least in part from the inability of current dialysis techniques to replace native kidney function. The commonly accepted guidelines recommend that dialysis dose should be based on measures of urea clearance even though it is recognized that urea is only a weak surrogate for the extent of uremia. Moreover, potentially more relevant uremic toxins [12] cannot be also monitored easily due to technical limitations. In this context a real-time, noninvasive, low-cost measurement method, which could be used routinely during each hemodialysis (HD) session, would be highly desirable.

There is growing evidence provided by a number of recent studies that the analysis of breath chemical fingerprint could serve as a non-invasive tool capable of detecting kidney failure and assessing hemodialysis efficiency. Breath levels of several volatile compounds have been found to be elevated in CKD patients and correlate well with other indicators of kidneys functions. Numerous investigators employing different lab-based analytical techniques identified breath ammonia as a potential marker for hemodialysis efficiency [13-16]. The observed, during the HD, decrease in breath $\mathrm{NH}_{3}$ concentrations correlated well with blood urea nitrogen (BUN) and creatinine. Dimethylamine (DMA) and trimethylamine (TMA) were reported to be elevated in patients with end-stage renal disease and decrease over the course of the HD treatment [13, 17]. Conversely, isoprene breath levels were found to be increased during and after hemodialysis [18, 19]. The monitoring of breath ethane provided evidence of a rapid rise of this compound during the first minutes after initiation of dialysis, which has been attributed to treatment-induced oxidative stress [20]. Recently, several sulphur containing compounds (e.g. dimethyl sulfide, methyl propyl sulfide) were documented to be eliminated from CKD breath during dialysis [21]. Furthermore, uremic breath was shown to provide information on the uremic syndrome and/or patient's exposure to the treatment-related (sometimes toxic) contaminants [21]. In view of these interesting findings breath analysis appears to be a novel interesting approach, which may, if successful, considerably improve the hemodialysis efficiency.
Table 1. Breath volatiles responding to the dialysis treatment

\begin{tabular}{|c|c|c|c|c|c|}
\hline \multirow{2}{*}{$\begin{array}{l}\text { Compound } \\
\text { (CAS) }\end{array}$} & \multirow[t]{2}{*}{$\begin{array}{l}\text { Applied } \\
\text { technique }\end{array}$} & \multicolumn{3}{|c|}{$\begin{array}{c}\text { Breath levels [ppb] mean } \\
\text { (range) }\end{array}$} & \multirow[t]{2}{*}{ Ref } \\
\hline & & $\begin{array}{l}\text { before } \\
\text { HD }\end{array}$ & $\begin{array}{l}\text { after } \\
\text { HD }\end{array}$ & control & \\
\hline $\begin{array}{l}\text { Ammonia } \\
(7664-41-7)\end{array}$ & $\begin{array}{l}\text { SIFT-MS, } \\
\text { IMS, laser } \\
\text { spectro- } \\
\text { scopy, } \\
\text { spectro- } \\
\text { photo- } \\
\text { metry, }\end{array}$ & $\begin{array}{l}4900 \\
(820- \\
14700)\end{array}$ & $<1000$ & $\begin{array}{l}960 \\
(425- \\
1800)\end{array}$ & [14] \\
\hline $\begin{array}{l}\text { Trimethyl- } \\
\text { amine } \\
(75-50-3)\end{array}$ & $\begin{array}{l}\text { GC-MS, } \\
\text { SIFT-MS }\end{array}$ & $\begin{array}{l}340 \\
(280- \\
520)\end{array}$ & $\begin{array}{l}63 \\
(46-220)\end{array}$ & $<30$ & [13] \\
\hline $\begin{array}{l}\text { Isoprene } \\
(78-79-5)\end{array}$ & $\begin{array}{l}\text { SIFT-MS, } \\
\text { PTR-MS, } \\
\text { GC-MS }\end{array}$ & $\begin{array}{l}138 \pm \\
63\end{array}$ & $184 \pm 90$ & $89 \pm 40$ & [18] \\
\hline $\begin{array}{l}\text { Ethane } \\
(74-84-0)\end{array}$ & $\begin{array}{l}\text { optical } \\
\text { spectro- } \\
\text { scopy, } \\
\text { GC }\end{array}$ & $\begin{array}{l}0.6 \\
(0-12)\end{array}$ & $\begin{array}{l}\text { Peak of } \\
5 \quad(3-8) \\
\text { ppb } \\
\text { during } \\
\text { dialisis }\end{array}$ & - & [20] \\
\hline $\begin{array}{l}\text { Dimethyl } \\
\text { sulfide } \\
(75-18-3)\end{array}$ & GC-MS & $\begin{array}{l}18.7 \\
(2.3- \\
146)\end{array}$ & $\begin{array}{l}5.7 \\
(1.2-39)\end{array}$ & $\begin{array}{l}5 \\
(1.4-28)\end{array}$ & [21] \\
\hline
\end{tabular}

Currently, the investigations of CKD-related breath chemical patterns rely on the laboratory-based sophisticated analytical techniques such as, gas chromatography- mass spectrometry (GC$\mathrm{MS}$ ), proton transfer reaction mass spectrometry (PTR-MS), selected ion flow tube mass spectrometry (SIFT-MS), laser spectroscopy, or ion mobility spectrometry IMS) and sensor boards. The analytical instruments provided by these techniques are inherently bulky, expensive, demand laborious and timeconsuming sample-preparation methods, and require well-trained and experienced operators. This places significant limitations on their routine application in clinical environment. Small sensorbased detectors targeting breath markers for dialysis efficiency could overcome these limitations and revolutionize the monitoring of therapeutic interventions in general and dialysis treatment in particular. 


\section{CONCLUSIONS}

Breath chemical analysis is a source of data that can be related with medical information. Gases and VOCs in expired air can be linked to diseases and metabolic disorders. Main challenges for integrating breath analysis in smartphones include the credibility of disease specific VOCs, the miniaturization of chemical sensors/instruments and the development of cost effective applications. The choice between the different mobile application development platforms should consider their features and trends. In one hand, hybrid applications pursue cross-platform portability; these are usually wrapped websites that allow quick results in return for specific design and performance. In the other hand, in case a native application is desired, Android and iOS are nowadays the most representative platforms. Android is open sourced and there are many devices from all major manufacturers to choose from, varying not only in price but also in screen size and specifications; so it has a larger user base and more potential users. Multiple users are allowed and, as a rule, they have more freedom. It should be mentioned that drawbacks include fragmentation and complexity of testing for many versions. iOS philosophy is to keep control, in software and hardware and to offer a smooth user experience. In this case, there is no way to expand physical storage, hardware is limited and cost is high. Windows Phone and Blackberry have a low market share.

The research in using breath analysis and smartphones for medical applications should consider the practical constraints and maturity levels of the corresponding sensor techniques. Moreover a multimodal, dynamic and context awareness filtering, and associated data-fusion techniques are essential to reduce the corresponding technological constraints of the associated VOCs sensors.

\section{ACKNOWLEDGMENTS}

Dedicated to the memory of our friend and colleague Prof. Anton Amann for his pioneer work in breath analysis.

\section{REFERENCES}

[1] Amann A. and Statheropoulos M. 2014. Chemical sensors integrated with mobile phones for remote medical diagnostics: state-of-the-art and beyond, MOBIHEALTH (Athens, Greece, November 3-5, 2014), DOI = http://dx.doi.org/10.4108/icst.mobihealth.2014.257397

[2] Gupta S., Breen P., Wu D. and Sabharwal A. 2010, "Breath analysis with laser sensors on an Android platform", Wireless Health '10, October 5-7, 2010, San Diego, USA., DOI $=$ http://dx.doi.org/10.1145/1921081.1921111

[3] Vamvakari J.,Mikedi K., Pallis C. G., Zorba E. andPappa A. 2015, A preliminary study of a novel mass spectrometry based system for monitoring gases and VOCs evolved during composting of green kitchen waste ,Anal. Methods, 2015, 7, 6243 , DOI $=10.1039 / \mathrm{c} 5 \mathrm{ay} 01313 \mathrm{e}$

[4] Fernandez F., Pallis C. G. 2014, Opportunities and challenges of the Internet of Things for healthcare: Systems engineering perspective, EAI 4th International Conference on Wireless Mobile Communication and Healthcare, 2014, DOI:110.1109/MOBIHEALTH.2014.7015961.
[5] Apple HealthKit and ResearchKit SDKhttps://developer.apple.com/healthkit/ https://developer.apple.com/researchkit/

[6] Samsung Digital Health and Wearable Gear SDK http://developer.samsung.com/health http://developer.samsung.com/gear

[7] Intel Edison development platform for SD card computers http://download.intel.com/support/edison/sb/edison_pb_3311 79001.pdf

[8] Texas Instruments. Bluetooth Low Energy Solutions. http://www.ti.com/lsds/ti/wireless_connectivity/bluetooth_bl uetooth-ble/overview.page?DCMP=bluvision\&HQS=ep-conlprf-bluvision-lp-bluetooth-pr-en

[9] Texas Instruments. SimpleLink SensorTag http://www.ti.com/ww/en/wireless_connectivity/sensortag20 15/?DCMP=sensortag-2015\&HQS=ep-con-lprf-sensortag2b-lp-en

[10] Review of development platforms for Bluetooth devices https://developer.bluetooth.org/DevelopmentResources/Deve lopmentPlatforms/Pages/Development-Platforms.aspx

[11] Zhang, Q.L. and D. Rothenbacher, Prevalence of chronic kidney disease in population-based studies: Systematic review. BMC Public Health, 2008. 8.

[12] Duranton, F., et al., Normal and Pathologic Concentrations of Uremic Toxins. Journal of the American Society of Nephrology, 2012. 23(7): p. 1258-1270.

[13] Endre, Z.H., et al., Breath ammonia and trimethylamine allow real-time monitoring of haemodialysis efficacy. Physiol Meas, 2011. 32(1): p. 115-30.

[14] Davies, S., P. Spanel, and D. Smith, Quantitative analysis of ammonia on the breath of patients in end-stage renal failure. Kidney Int, 1997. 52(1): p. 223-8.

[15] Rolla, G., et al., Breath analysis in patients with end-stage renal disease: effect of haemodialysis. Eur J Clin Invest, 2008. 38(10): p. 728-33.

[16] Narasimhan, L.R., W. Goodman, and C.K. Patel, Correlation of breath ammonia with blood urea nitrogen and creatinine during hemodialysis. Proc Natl Acad Sci U S A, 2001. 98(8): p. $4617-21$

[17] Simenhoff, M.L., et al., Biochemical profile or uremic breath. N Engl J Med, 1977. 297(3): p. 132-5.

[18] Davies, S. Et al., A new online method to measure increased exhaled isoprene in end-stage renal failure. Nephrol. Dial. Transplant., 2001. 16:p. 836-839

[19] Lirk, P., et al., Elective haemodialysis increases exhaled isoprene. Nephrol Dial Transplant, 2003. 18(5): p. 937-41.

[20] Stevenson, K.S., et al., Breath ethane peaks during a single haemodialysis session. J Breath Res, 2008. 2(2): p. 026004.

[21] Mochalski, P., et al., Blood and breath profiles of volatile organic compounds in patients with end-stage renal disease. BMC Nephrol, 2014. 15. 